\title{
Factors associated with healthcare seeking behaviour for children in Malawi: 2016
}

Wingston $\mathrm{Ng}^{\prime} \mathrm{ambi}^{1}$, Tara Mangal ${ }^{2}$, Andrew Phillips ${ }^{3}$, Tim Colbourn ${ }^{3}$, Joseph Mfutso-Bengo ${ }^{1}$, Paul Revill5, Timothy B. Hallett ${ }^{2}$

${ }^{1}$ University of Malawi, College of Medicine, Health Economics and Policy Unit, Lilongwe, Malawi 2Imperial College London, London, UK

${ }^{3}$ University College London, London, UK

${ }^{4}$ Ministry of Health, Department of Planning and Policy, Lilongwe, Malawi

${ }^{5}$ University of York, York, UK

\section{ABSTRACT}

Objective: To characterize health seeking behavior (HSB) and determine its predictors amongst children in Malawi in 2016.

Methods: We used the 2016 Malawi Integrated Household Survey dataset. The outcome of interest was HSB, defined as seeking care at a health facility amongst people who reported one or more of a list of possible symptoms given on the questionnaire in the past two weeks. We fitted a multivariate logistic regression model of HSB using a forward step-wise selection method, with age, sex and symptoms entered as a priori variables.

Results: Of 5350 children, 1666 (32\%) had symptoms in the past two weeks. Of the 1666, 1008 (61\%) sought care at health facility. The children aged 5 to 14 years were less likely to be taken to health facilities for healthcare than those aged 0 to 4 years. Having fever vs. not having fever and having a skin problem vs. not having skin problem were associated with increased likelihood of HSB. Having a headache vs. not having a headache was associated with lower likelihood of accessing care at health facilities (AOR= $0.50,95 \% \mathrm{Cl}: 0.26-0.96, \mathrm{P}=0.04)$. Children from urban areas were more likely to be taken to health facilities for healthcare $(A O R=1.81,95 \% \mathrm{Cl}: 1.17-2.85, \mathrm{P}=0.008)$, as were children from households with a higher socioeconomic position $(\mathrm{AOR}=1.96,95 \% \mathrm{Cl}: 1.13-3.40, \mathrm{P}=0.02)$.

Conclusion: There is a need to understand and address individual, socioeconomic and geographical barriers to health seeking to increase access and use of healthcare and fast-track progress towards Universal Health Coverage.

Key words: Malawi; Healthcare Seeking Behaviour; Determinants of Health

This article has been accepted for publication and undergone full peer review but has not been through the copyediting, typesetting, pagination and proofreading process, which may lead to differences between this version and the Version of Record. Please cite this article as doi: $\underline{10.1111 / \text { TMI.13499 }}$

This article is protected by copyright. All rights reserved 


\section{INTRODUCTION}

Health seeking behaviour (HSB) refers to action taken by individuals when ill in order to find appropriate remedies [1] [2]. HSB is a good predictor of health service utilisation at community level and can be affected by educational levels, economic factors, cultural beliefs and practices, socio-demographic factors, knowledge about the facilities, gender issues, and the health care system itself [3] [4]. HSB is preceded by a decision-making process governed by individual or household behaviour, community norms, and expectations, as well as provider-related characteristics [2]. Studies conducted in Malawi and Uganda have identified disparities in HSB by geographic location with certain communities having more access to health services than others [3] [5] [6].

Studies assessing the barriers to HSB for carers of children in Ethiopia, Kenya, Malawi, Tanzania and South Africa have found significant impacts of socioeconomic status, male sex, lack of awareness of the need for primary care, cultural beliefs, peer influences, distance and cost [7] [8] [9] [10] [11]. The probability of HSB varies by age, sex, location and socio-economic position in settings in sub-Saharan Africa. Specifically, HSB has been higher in the rural population and those with a higher socio-economic position among other factors [7] [12].

Most of the studies conducted on HSB of children in Malawi have considered HSB in specific districts or urban or rural settings and analyzed one illness at a time. There is a dearth of knowledge on factors associated with more generalized HSB in Malawi among children. Therefore, we aimed to characterize healthcare seeking behaviour and determine its predictors amongst carers of children in Malawi in 2016. We specifically estimated the probability of healthcare seeking given the presence of specific symptoms and determined the factors associated with HSB among children from households interviewed during the 2016 integrated household survey (IHS) in Malawi.

\section{METHODS}

\section{Study Design and Introduction to Integrated Household Survey}

We examine the factors associated with HSB using a cross-section sub-sample of children in the Malawi IHS 2016 [13]. The IHS are implemented by the Government of Malawi through the National Statistical Office (NSO) as part of the World Bank Living Standards Measurement Study - Integrated Surveys on Agriculture (LSMS-ISA) initiative[13]. The Integrated Household Survey is one of the primary instruments implemented by the Government of Malawi through the National Statistical Office (NSO) roughly every 5 years to monitor and evaluate the changing conditions of Malawian households. The IHS data have, among other insights, provided benchmark poverty and vulnerability indicators to foster evidence-based policy formulation and monitor the progress of meeting the Millennium Development Goals (MDGs), the 
goals listed as part of the Malawi Growth and Development Strategy (MGDS) and now the Sustainable Development Goals (SDGs) [14].

The training of enumerators was conducted from 22 February 2016 to 25 March 2016 [14]. The NSO trained 110 research assistants. Of these, 18 were earmarked for team leaders and 92 were earmarked for data collection [14]. Of the 92 enumerators, 20 were kept on reserve to replace those who would leave in the process of data collection. There were 18 mobile teams each covering approximately two districts. Each team had a team leader, 4 enumerators, and a driver. Data collection started on the 15th of April 2016 and finished on 30 April 2017 [14].

The IHS has a number of modules that were relevant to this study. The household roster contained demographic data on all the members of the interviewed households. The health section contained information on symptoms in the past two weeks and any resulting health care seeking behaviour. Furthermore, both non-chronic and chronic conditions were captured in this section. Households were asked to provide a maximum of two symptoms experienced by each household member in the preceding two weeks. Although the pre-populated list had thirty symptoms included in the survey questionnaire, by design of the questionnaire only two symptoms were allowed to be reported by the household member.

\section{Sampling Procedure}

The IHS applied a two-stage sampling procedure and used a nationally representative sample. The sampling frame was based on the 2008 Malawi Population and Housing Census [15]. The primary sampling units (PSUs) were the census enumerations areas (EAs) defined for the 2008 Malawi Population and Housing Census. The EA is the smallest operational area established for the census with well-defined boundaries and has an average of about 235 household [15].

\section{Data Management}

From the household roster of the IHS questionnaire we obtained age, sex (male/female), residence (rural/urban), district, region of residence (North/Central/Southern), carer level of education (none/primary/tertiary), and sampling weights. From the health section of the IHS questionnaire we extracted information on whether the child experienced any symptoms in the past two weeks, name of symptom, HSB (visiting or not visiting a health facility). The symptoms were mapped as shown in Box 1. During mapping, we grouped similar symptoms together as follows: fever or malaria (if they had fever or malaria), diarrhoea or vomiting (if they had diarrhea or were vomiting), sore throat (if they had sore throat and ear/nose/throat problems) and respiratory tract infections (if they had upper respiratory (sinuses), lower respiratory (chest, lungs), and flu) and other, including fainting, feeling pain when passing urine, mental disorder, tuberculosis, sexually transmitted infections, unspecified long-term illnesses, and 
other illnesses.

HSB was equal to 1 if the person sought healthcare from private, government or faith-based health facilities as well as village health clinics and local pharmacies while HSB was equal to 0 if people did not access healthcare, or sought care through alternative providers, for example traditional or faith healers. In this analysis we included only persons aged up to 14 years.

We computed the wealth quintile, proxy for wealth status, using factor analysis using an algorithm outlined by Measure Demographic and Health Surveys [16]. Wealth quintile is an asset-based measure employed in locations where incomes are difficult to measure [17]. Assets including livestock and birds (goats, sheep, cattle, donkeys, pigs and chicken), utilities (electricity and running water), type of dwelling and other properties such as radio sets were used to construct our wealth quintiles [17]. In this study, we used the following to compute the wealth quintile: (a) Floor material (sand, smoothed mud, smooth cement, tile, other), (b) cooking fuel (firewood, crop residue, other, paraffin, electricity, charcoal), (c) water supply (personal open unprotected well, communal open unprotected well, river, spring, lake, reservoir, other, piped into dwelling, piped outside dwelling, communal standpipe, personal hand-pump, communal hand-pump, protected spring), (d) toilet facility (no toilet facility, other, flush toilet, VIP latrine, traditional latrine with roof, latrine without roof), and (e) ownership of assets (bed, chair, table, radio, television, bicycle, motorcycle, and car or bus). We generated the tertiles and ranked them from the lowest to the highest in line with the Measure Demographic and Health Surveys [16]. The wealth index tertiles were derived from the quintiles in which the bottom two were combined and the upper two categories of the quintiles were combined in order to come up with the wealth index tertiles.

Box 1: Showing mapping of thirty symptoms captured into fifteen symptoms using the 2016 Malawi Integrated Household Survey

\begin{tabular}{|l|l|}
\hline Symptom from survey & Mapped to the variable \\
\hline Fever and Malaria & Fever/Malaria \\
\hline Diarrhoea and Vomiting & Vomiting/Diarrhoea \\
\hline Stomach Ache & Stomach Ache \\
\hline Sore Throat and Ear/Nose/Throat & Sore Throat \\
\hline Upper Respiratory (Sinuses), Lower Respiratory (chest, lungs), and Flu & Respiratory Infection \\
\hline Headache & \\
\hline
\end{tabular}

This article is protected by copyright. All rights reserved 


\begin{tabular}{|l|l|}
\hline Skin Problem & Skin Problem \\
\hline Dental Problem & Dental Problem \\
\hline Eye Problem & Eye Problem \\
\hline Backache & Backache \\
\hline Burn, Fracture and Wound & Injuries \\
\hline $\begin{array}{l}\text { Fainting, Pain when Passing Urine, Mental Disorder, Tuberculosis, } \\
\text { Unspecified Long-term Illnesses, and Other Illnesses }\end{array}$ & Other \\
\hline
\end{tabular}

\section{Data Analysis}

We calculated frequency, proportions, odds ratios (OR) and their associated $95 \%$ confidence intervals $(95 \% \mathrm{CI})$. Data were analysed with STATA 15.1 (Stata Corp., Texas, USA). We weighted all household level analyses as detailed above, and performed both bivariate and multivariate analyses of the effect of sociodemographic factors of the carer and symptoms on the binary endpoint of HSB. We fitted a multilevel mixed-effects logistic regression model of HSB using a forward step-wise selection method. Child's age, sex and reported symptoms were entered as a priori variables in the multivariate model. To determine whether a factor was included in the model, the likelihood ratio test (LRT) was used. We set the level of statistical significance at $\mathrm{P}<0.05$.

\section{Ethical Considerations}

We obtained permission to use this data from the World Bank to access the Malawi IHS datasets from https://microdata.worldbank.org/index.php/catalog/2939. Furthermore, this study was approved by the College of Medicine Research Committee (COMREC) in Blantyre, Malawi (protocol \#: P.10/19/2820). As this study used secondary anonymised data, the issue of individual informed consent did not apply.

\section{RESULTS}

\section{Characteristics of children from interviewed households in Malawi}

The characteristics of the children included in the study are shown in Table 1. A total of 5350 children were evaluated in the 2016 IHS survey round. $52 \%$ were girls, and $83 \%$ of the children were from rural areas. The majority were aged between 5 and 14 years rather than under 5 years (Table 1 ). The overall median age of the children was 7 years (interquartile range (IQR):3-11).

The largest number of children were from the southern region while the least number were from the northern region (Table 1). $45 \%$ of children came from households of low wealth index; $31 \%$ from households of high wealth index (31\%). There were fewer children from households with a household 
head of at least 60 years than children from houses with household heads of 35 to 59 years of age (Table 1). A total of 4951 ( $94 \%$ of 5350 ) children were from households where the head had no formal education.

\section{Symptoms within the past two weeks prior to survey amongst children in Malawi}

As Table 1 shows, $32 \%$ of the 5350 children had symptoms in the past two weeks. A higher proportion of children from rural than urban areas reported symptoms. There were regional variations in the proportions of children with symptoms; with children from the southern region being less likely to be ill compared to those from either the central or northern region $(P=0.0001)$. A significantly higher proportion of children under 5 years had symptoms than older children $(P<0.001)$. A lower proportion of children from rich households had symptoms than those from the poor households $(P=0.001)$. The proportion of boys and girls who had symptoms in the past fourteen days was similar.

Amongst the 1666 children with symptoms within the past two weeks, the most common symptoms reported were fever ( $48 \%$ of 1666$)$, followed by respiratory tract infections ( $15 \%$ of 1666$)$ and then headache (9\% of 1666) as shown in Table 2a. The least common illnesses reported were dental problems ( $0.4 \%$ of 1666$)$, eye problems ( $1 \%$ of 1666 ) and skin problems ( $4 \%$ of 1666$)$. No child reported back pain in the two weeks prior to the survey. A total of $231(4 \%)$ of the 5350 children had chronic conditions. Of these, $127(58 \%)$ had been ill within the previous two weeks. The numbers and percentages of children with chronic conditions are shown in Table $2 \mathrm{~b}$. The most common chronic condition was asthma (6\%) while the rarest was arthritis (0.1\%).

\section{Places where children were taken for healthcare}

The places where the children were taken for healthcare are shown in Table 3. Of the 1666 children reporting symptoms, 1573 (94\%) were taken for health care while 93 (6\%) were not due to lack of money or illness being perceived as not serious. Of those that were taken for healthcare, 1008 (64\% of 1573) were taken to a healthcare facility; 756 (45\%) sought care from government health facilities and 146 (9\%) from private clinics. Amongst the 659 children that were not taken for care at a health facility, 408 (62\%) bought medicines from grocery stores and $105(16 \%)$ used the medicines that they had in stock at their homes.

There were 127 children with chronic conditions. Of these, 90 (70\%) were taken to health facilities for health care while $37(30 \%)$ that did not seek health care from hospitals. Amongst those who did not seek care from hospitals, 22 (59\%) bought drugs from the grocery stores while the remainder used herbal medicine $(9 \%)$ or did nothing $(32 \%)$.

This article is protected by copyright. All rights reserved 


\section{Factors associated with healthcare seeking behaviour for children in Malawi}

\section{Bivariate Analysis of Health Seeking Behaviour}

Overall, $60 \%$ of the children were taken for health care in the health facilities (Table 1). The proportion of children that received health care from health facilities varied by region $(P=0.02)$ with the northern region having the highest proportion (72\% of 185 ) while the fewest were observed in the central region (57\% of 816). HSB was higher in urban than rural areas (Table 1). There was similar HSB for boys and girls in Malawi in 2016. Children aged 0 to 4 years had a significantly higher HSB than those aged 5 to 14 years $(P=0.001)$. The children from households of higher wealth status had higher HSB than those from households of lower wealth status ( $68 \%$ of 539 vs. $55 \%$ of 778 respectively). The distribution of children taken for health care at facility was similar by age of the household head (Table 1).

Healthcare seeking behaviour also varied by type of symptom of the child as shown in Table 2 . The highest health seeking behaviour was observed amongst children with skin problems (78\%), followed by those with fever (71\%) and those with eye problems (67\%).

\section{Multivariate Analysis of Health Seeking Behaviour}

The factors associated with health seeking behaviour are shown in Table 4. Health seeking behaviour varied by age of child, residence, socio-economic position, comorbidity with chronic conditions, and reported symptom. After adjusting for sex and child's symptom, the children aged 5 to 14 years were less likely to be taken for healthcare at health facilities than the children aged 0 to 4 years $(A O R=0.50,95 \% \mathrm{Cl}$ : 0.37-0.67, $\mathrm{P}<0.001)$. Having fever compared to not having fever ( $\mathrm{AOR}=3.52,95 \% \mathrm{Cl}: 1.95-6.37, \mathrm{P}<0.001)$ and skin problem vs. no skin problem (AOR=3.45, 95\% Cl: $1.37-8.72, \mathrm{P}=0.01)$ were associated with higher likelihood of accessing care at health facilities. However, having a headache was associated with lower likelihood ( $\mathrm{AOR}=0.47,95 \% \mathrm{Cl}: 0.27-0.92, \mathrm{P}=0.03)$ of accessing care at health facilities. Children from the central region had a lower likelihood of accessing care at health facilities than those from northern and southern regions (Table 4).

The socio-economic factors like residence and wealth status were also associated with HSB. The children from urban areas had almost twice the likelihood of HSB than the children from the rural households ( $A O R=1.75,95 \% \mathrm{Cl}$ : 1.12-2.72, $\mathrm{P}=0.01)$. Compared to children from poorer households, children from wealthier households were more likely to be taken for healthcare at health facilities ( $A O R=1.86,95 \% \mathrm{Cl}: 1.25-2.78, \mathrm{P}=0.02$ ). Children with chronic conditions were more likely to be taken for care to health facilities than those without chronic conditions ( $A O R=2.13,96 \% \mathrm{Cl}: 1.23-3.68, \mathrm{P}=0.01$ ).

This article is protected by copyright. All rights reserved 


\section{DISCUSSION}

We investigated the health seeking behaviour of carers of a representative sample of children in Malawi using the Malawi IHS dataset. This is the first national-level study analyzing HSB due to a broad range of symptoms amongst the children of Malawi. In this study, there are five key findings: (a) $32 \%$ of the children had some symptoms in the past two weeks; (b) of these, $60 \%$ sought health care from a health care facility; (c) fever (47\%), respiratory tract infections (15\%) and headache (9\%) were the three most common symptoms reported; (d) $75 \%$ of the children obtained healthcare from government health facilities while $14 \%$ sought health care from private clinics; and (e) type of illness, residence, age, region and wealth status were the main determinants for taking children to access care at health facilities.

In contrast to a study conducted in Tanzania, this study had 7\% higher proportion of children with at least one illness in the past two weeks [18]. Similar to other studies in sub-Saharan Africa, fever is amongst the most common childhood illness [8] [19]. Some studies conducted in Sub-Saharan Africa (SSA) have also shown variations in HSB by symptoms and age [8] [19] [20]. Amongst those not seeking healthcare from a healthcare facility, a similar sizable majority consulting either drug sellers or using selftreatment was observed. Although this study found high HSB among children, approximately $16 \%$ lower than studies conducted among children with fever, cough and diarrhea in Ethiopia [8] [19]. Compared to some studies conducted in Ethiopia [21] [22], this study had higher HSB.

Similar to this study, the majority of the children that sought care were taken to government health facilities in studies done in SSA [8] [19]. The observed differences could be due to focusing on a subpopulation compared to general population in our case. Amongst the under-five children, this study has a slightly higher health seeking behavior than obtained in a Malawian study by Lungu et al [23]. Accessing care from private clinics ranged from $30 \%$ to $85 \%$ for one study involving children with pneumonia in SSA [24]; but the average proportion of children brought to care was higher than in this study (approximately 78\%). Approximately, $1 \%$ of the children with pneumonia in one study covering Uganda, Nigeria, Ethiopia, Tanzania, Burkina Faso and Democratic Republic of Congo (DRC) [24] were taken to private clinics while in this study we found $14 \%$ of the children that were taken to private clinics. The differences in accessing care from private clinics may be attributable to country specific health system programming like subsidies of patient fees for faith-based facilities in Malawi - which may not be the case in the other countries.

There is not much literature in Africa on the association between HSB and skin disease. However, in one study conducted rural Tanzania indicated that HSB amongst the children with skin diseases was approximately $48 \%$ [18]. The major reason for higher HSB in the Malawian children may be attributable to free healthcare whilst in other countries patient fees apply. For example, in Tanzania most of the parents 
took their children to traditional healers because the service was cheaper than at the government or faith-based health facilities [18].

We found weak evidence of association between HSB and sex of the child. However, a study conducted in Nigeria has shown that HSB was almost three-fold higher for boys than girls [25]. The weak evidence in association between HSB and child's sex in Malawi may be attributable to the implementation of child healthcare related byelaws in the country. One example of byelaw is imposing fines on women for delivering at home, in the form of goats, chickens and money [26] [27] or fining parents who do not take their children to health facilities once the children are sick.

There are several policy implications of the study findings. First, we noted that health seeking behaviour varied with age of the child. Specifically, we found that older children aged 5 to 14 years were less likely to be taken to a health facility as observed in some studies conducted in Malawi, Ghana and Nigeria [23] [28] [29]. Furthermore, children with fever had higher likelihood of HSB, as shown in similar studies [30] [31]. In Malawi, there was higher proportion of HSB amongst those with vomiting and diarrheal symptoms compared to Tanzania [32]. We also observed higher likelihood of HSB in Malawi than in Tanzania amongst the persons with fever or malaria compared with other symptoms [33]. There is a need to conduct further research in order to understand the barriers and facilitators of health care seeking behaviour amongst the care givers of children below 15 years in Malawi. Such a study needs to use both qualitative and quantitative methods of data collection.

Secondly, HSB was also lower in the rural areas compared to the urban areas. Of the total population in Malawi, $16 \%$ live in urban areas while $84 \%$ live in rural areas [34]. Therefore, the majority of Malawi may not be accessing health care from health facilities because the facilities are far from their homes. The low coverage of health services in rural areas of Malawi is often exacerbated by the high costs related to reaching health facilities [35]. Some similar studies in resource limited settings have cited distance to the facilities [36] or unavailability of health services to be associated with lower HSB amongst the rural populations [37]. A multi-country study conducted in SSA shows that people in Malawi took the least time to their nearest health facility compared to other countries [38]. However, amongst the rural populations, access to local health centers or hospitals is often constrained by a lack of transport and inability to meet the direct and indirect costs of a clinic visit [30]. One option to provide health services to the rural population may to provide more outreach clinics and provision of transport for children from hard-toreach areas.

We also observed that children with chronic illnesses had a higher likelihood of being taken for care at health facilities. A study conducted in Malawi has shown that understanding of health and disease determined the decision to seek health care as well as the place to seek health care amongst persons with 
chronic conditions in Malawi [39].

Some studies conducted in Sub-Saharan Africa have shown that HSB is associated with socio economics of the society[40] [41]. In this study we did find strong evidence of associations between wealth status of carers of children and the associated HSB. Similar to a study conducted in Nigeria [28], this study found that children from households of higher wealth status are more likely to access care at health facility and this may be attributable to the most of the rich households being able to pay for healthcare. Furthermore, most of the rich households can afford medical insurance hence they are more likely to take their children to accessing care at health facilities.

The major strengths of this study were the large sample size and its representativeness, which potentially allows the analysis to improve operational practice and inform policy change. The study findings have the potential to inform management of children in Malawi and other similar settings especially with regard to HSB of their caregivers. The study depended on reported information on symptoms of the child by the household key respondent, therefore, some symptoms may have been omitted either intentionally or due to recall lapse. However, in this study we are unable to estimate the extent of underestimation or overestimation of the reported symptoms and their associated HSB.

The other major limitation of the study includes only capturing up to two symptoms per child. The children may have had more than two symptoms and that minimized the actual interplay of the symptoms on likelihood for accessing care at health facilities. Furthermore, the IHS did not capture time it took for care to be sought hence we are unable to determine whether care was obtained late or promptly. The IHS did not capture the distance from the household to the nearest health facility where the child was more likely to be taken for healthcare for the illnesses although there is literature that shows that distance to health facility is associated with HSB. This analysis has not considered the effect of interactions between symptoms on HSB of parents and children. Besides, this analysis did not consider the caregiver perceptions, reasons to seek or not to seek health care services as such data were not available albeit crucial for understanding the HSB. We also recognize that the interviews were conducted at different times of the year and this has implications on the seasonal bias on the findings of the reported symptoms as well as their associated HSB. In this analysis, we have not taken into account seasonal variations of the reported symptoms as well as their associated HSB.

In conclusion, HSB for children in Malawi is common; children with fever, chronic conditions and skin problems had a higher likelihood of HSB while children aged 5 to 14 years and those with headache had lower probability of HSB than those aged 0 to 4 years. We also found that children from urban areas and households with higher wealth status were more likely to be taken for healthcare at health facilities. To achieve universal health coverage, government policies and programmes should take these factors into 
account in health care programming in order to improve population health and reduce health inequalities in Malawi.

\section{Availability of data and materials}

The data are available for download from https://microdata.worldbank.org/index.php/catalog/2939. The STATA do-file for this study can be requested from the corresponding author.

\section{ACKNOWLEDGEMENTS}

The authors would like to thank the World Bank for granting access to use the datasets for Malawi. Funding for this project was provided to the University of York to implement the Thanzi la Onse (TLO) Programme by the Research Council of the United Kingdom (RCUK). During the study period, WN, TM, AP, TC, DN, JMB, GM, PR and TBH worked for a RCUK funded project.

\section{REFERENCES}

[1] Editorial Health Seeking Behaviour in Context. 2003. [Last cited on 2019 Apr 11]. Available from: http://www.ajol.info/index.php/eamj/article/viewFile/8689/1927. .

[2] S. Oberoi, N. Chaudhary, S. Patnaik, and A. Singh, "Understanding health seeking behavior," Journal of family medicine and primary care, vol. 5, no. 2, pp. 463-464, 2016, doi: 10.4103/22494863.192376.

[3] D. Musoke, P. Boynton, C. Butler, and M. B. Musoke, "Health seeking behaviour and challenges in utilising health facilities in Wakiso district, Uganda," African health sciences, vol. 14, no. 4, pp. 10461055, Dec. 2014, doi: 10.4314/ahs.v14i4.36.

[4] D. Clewley, D. Rhon, T. Flynn, S. Koppenhaver, and C. Cook, "Health seeking behavior as a predictor of healthcare utilization in a population of patients with spinal pain," PLOS ONE, vol. 13, no. 8, p. e0201348, Aug. 2018, doi: 10.1371/journal.pone.0201348.

[5] A. I. Chibwana, D. P. Mathanga, J. Chinkhumba, and C. H. Campbell, "Socio-cultural predictors of health-seeking behaviour for febrile under-five children in Mwanza-Neno district, Malawi," Malaria Journal, vol. 8, no. 1, p. 219, Sep. 2009, doi: 10.1186/1475-2875-8-219.

[6] L. N. Kazembe, C. C. Appleton, and I. Kleinschmidt, "Choice of treatment for fever at household level in Malawi: examining spatial patterns," Malaria Journal, vol. 6, no. 1, p. 40, Apr. 2007, doi: 10.1186/1475-2875-6-40.

[7] P. Natalie Spark-du, Health-seeking behaviour for childhood illnesses in urban South Africa. 2013.

[8] G. T. Weldesamuel, T. T. Alemayoh, H. T. Atalay, and T. M. Zemichael, "Modern health-seeking 
behaviour and associated factors among mothers having under 5-years old children in Shire town, Tigray, Ethiopia: A cross-sectional study 2018," Afr J Prim Health Care Fam Med, vol. 11, no. 1, pp. e1e6, Aug. 2019, doi: 10.4102/phcfm.v11i1.1913.

[9] A. Abubakar, A. Van Baar, R. Fischer, G. Bomu, J. K. Gona, and C. R. Newton, "Socio-Cultural Determinants of Health-Seeking Behaviour on the Kenyan Coast: A Qualitative Study," PLOS ONE, vol. 8, no. 11, p. e71998, Nov. 2013, doi: 10.1371/journal.pone.0071998.

[10] M. Ustrup et al., "Potential barriers to healthcare in Malawi for under-five children with cough and fever: a national household survey," J Health Popul Nutr, vol. 32, no. 1, pp. 68-78, Mar. 2014.

[11] E. A. Lungu, R. Biesma, M. Chirwa, and C. Darker, "Healthcare seeking practices and barriers to accessing under-five child health services in urban slums in Malawi: a qualitative study," BMC Health Services Research, vol. 16, no. 1, p. 410, Aug. 2016, doi: 10.1186/s12913-016-1678-x.

[12] A. C. Noordam, L. Carvajal-Velez, A. B. Sharkey, M. Young, and J. W. L. Cals, "Care Seeking Behaviour for Children with Suspected Pneumonia in Countries in Sub-Saharan Africa with High Pneumonia Mortality," PLOS ONE, vol. 10, no. 2, p. e0117919, Feb. 2015, doi: 10.1371/journal.pone.0117919.

[13] National Statistical Office, "Malawi Fourth Integrated Household Survey (IHS4) 2016-2017: Basic Information." National Statistical Office, Nov. 2017, Accessed: Sep. 25, 2019. [Online].

[14] NSO, “INTEGRATED HOUSEHOLD SURVEY 2016-2017." Malawi Government, Nov. 2017, Accessed: Sep. 02, 2020. [Online]. Available: http://www.nsomalawi.mw/images/stories/data_on_line/economics/ihs/IHS4/IHS4\%20REPORT.pdf.

[15] National Statistical Office, "MALAWI INTEGRATED HOUSEHOLD SURVEY 2010-2011: HOUSEHOLD SOCIO-ECONOMIC CHARACTERISCTICS REPORT." National Statistical Office, Sep. 2012, Accessed: Sep. 25, 2019. [Online].

[16] S. O. Rutstein, "The DHS wealth index: Approaches for rural and urban areas," Macro International, Calverton, Maryland, USA, 2008. [Online]. Available: http://dhsprogram.com/pubs/pdf/WP60/WP60.pdf.

[17] V. Z. Kuuire, E. Bisung, A. Rishworth, J. Dixon, and I. Luginaah, "Health-seeking behaviour during times of illness: a study among adults in a resource poor setting in Ghana," Journal of Public Health, vol. 38, no. 4, pp. e545-e553, Nov. 2015, doi: 10.1093/pubmed/fdv176.

[18] F. T. Satimia, S. R. McBride, and B. Leppard, "Prevalence of Skin Disease in Rural Tanzania and Factors Influencing the Choice of Health Care, Modern or Traditional," Archives of Dermatology, vol. 134, no. 11, pp. 1363-1366, Nov. 1998, doi: 10.1001/archderm.134.11.1363.

[19] T. Kolola, T. Gezahegn, and M. Addisie, "Health Care Seeking Behavior for Common Childhood Illnesses in Jeldu District, Oromia Regional State, Ethiopia," PLOS ONE, vol. 11, no. 10, p. e0164534,

This article is protected by copyright. All rights reserved 
Oct. 2016, doi: 10.1371/journal.pone.0164534.

[20] "Sampson, Emilia Oluchi (2018) Factors associated with health seeking behavior for malaria treatment among caregivers of under-five children with fever in Imo State, Nigeria. Masters thesis, Universiti Putra Malaysia." .

[21] T. Astale and M. Chenault, "Help-Seeking Behavior for Children with Acute Respiratory Infection in Ethiopia: Results from 2011 Ethiopia Demographic and Health Survey," PLoS One, vol. 10, no. 11, pp. e0142553-e0142553, Nov. 2015, doi: 10.1371/journal.pone.0142553.

[22] N. T. Abegaz, H. Berhe, and G. B. Gebretekle, "Mothers/caregivers healthcare seeking behavior towards childhood illness in selected health centers in Addis Ababa, Ethiopia: a facility-based crosssectional study," BMC Pediatrics, vol. 19, no. 1, p. 220, Jul. 2019, doi: 10.1186/s12887-019-1588-2.

[23] E. A. Lungu, C. Darker, and R. Biesma, "Determinants of healthcare seeking for childhood illnesses among caregivers of under-five children in urban slums in Malawi: a population-based cross-sectional study," BMC Pediatr, vol. 20, no. 1, pp. 20-20, Jan. 2020, doi: 10.1186/s12887-020-1913-9.

[24] A. C. Noordam, L. Carvajal-Velez, A. B. Sharkey, M. Young, and J. W. L. Cals, "Care seeking behaviour for children with suspected pneumonia in countries in sub-Saharan Africa with high pneumonia mortality," PLoS One, vol. 10, no. 2, pp. e0117919-e0117919, Feb. 2015, doi: 10.1371/journal.pone.0117919.

[25] S. E. Oluchi, R. A. Manaf, S. Ismail, and T. K. Udeani, "Predictors of Health-Seeking Behavior for Fever Cases among Caregivers of Under-Five Children in Malaria-Endemic Area of Imo State, Nigeria," Int J Environ Res Public Health, vol. 16, no. 19, p. 3752, Oct. 2019, doi: 10.3390/ijerph16193752.

[26] L. Manda-Taylor et al., "Changing times? Gender roles and relationships in maternal, newborn and child health in Malawi," BMC Pregnancy Childbirth, vol. 17, no. 1, pp. 321-321, Sep. 2017, doi: 10.1186/s12884-017-1523-1.

[27] A. Walsh et al., "The role of the traditional leader in implementing maternal, newborn and child health policy in Malawi," Health Policy and Planning, vol. 33, no. 8, pp. 879-887, Jul. 2018, doi: 10.1093/heapol/czy059.

[28] T. A. Ogunlesi and D. M. Olanrewaju, "Socio-demographic Factors and Appropriate Health Careseeking Behavior for Childhood Illnesses," Journal of Tropical Pediatrics, vol. 56, no. 6, pp. 379-385, Feb. 2010, doi: 10.1093/tropej/fmq009.

[29] A. C. Noordam, L. Carvajal-Velez, A. B. Sharkey, M. Young, and J. W. L. Cals, "Care Seeking Behaviour for Children with Suspected Pneumonia in Countries in Sub-Saharan Africa with High Pneumonia Mortality," PLOS ONE, vol. 10, no. 2, p. e0117919, Feb. 2015, doi: 10.1371/journal.pone.0117919.

[30] B. Adhikari et al., "Treatment-seeking behaviour for febrile illnesses and its implications for malaria 
control and elimination in Savannakhet Province, Lao PDR (Laos): a mixed method study," BMC Health Serv Res, vol. 19, no. 1, pp. 252-252, Apr. 2019, doi: 10.1186/s12913-019-4070-9.

[31] Y. A. Gelaw, G. A. Biks, and K. A. Alene, "Effect of residence on mothers' health care seeking behavior for common childhood illness in Northwest Ethiopia: a community based comparative cross sectional study," BMC Research Notes, vol. 7, no. 1, p. 705, Oct. 2014, doi: 10.1186/1756-0500-7-705.

[32] J. O. Akinyemi, P. Banda, N. De Wet, A. E. Akosile, and C. O. Odimegwu, "Household relationships and healthcare seeking behaviour for common childhood illnesses in sub-Saharan Africa: a cross-national mixed effects analysis," BMC Health Serv Res, vol. 19, no. 1, pp. 308-308, May 2019, doi: 10.1186/s12913-019-4142-x.

[33] J. Adinan, D. J. Damian, N. R. Mosha, I. B. Mboya, R. Mamseri, and S. E. Msuya, "Individual and contextual factors associated with appropriate healthcare seeking behavior among febrile children in Tanzania," PLoS One, vol. 12, no. 4, pp. e0175446-e0175446, Apr. 2017, doi:

10.1371/journal.pone.0175446.

[34] National Statistical Office, "2018 Malawi Population and Housing Census- Main Report." National Statistical Office, May 2019, Accessed: Sep. 03, 2019. [Online]. Available: http://www.nsomalawi.mw/images/stories/data_on_line/demography/census_2018/2018\%20Mala wi\%20Population\%20and\%20Housing\%20Census\%20Main\%20Report.pdf.

[35] G. A. Abiiro, G. B. Mbera, and M. De Allegri, "Gaps in universal health coverage in Malawi: A qualitative study in rural communities," BMC Health Services Research, vol. 14, no. 1, p. 234, May 2014, doi: 10.1186/1472-6963-14-234.

[36] M. Das, F. Angeli, A. J. S. M. Krumeich, and O. C. P. van Schayck, "The gendered experience with respect to health-seeking behaviour in an urban slum of Kolkata, India," Int J Equity Health, vol. 17, no. 1, pp. 24-24, Feb. 2018, doi: 10.1186/s12939-018-0738-8.

[37] C. Anthonj, P. Giovannini, and T. Kistemann, "Coping with ill-health: health care facility, chemist or medicinal plants? Health-seeking behaviour in a Kenyan wetland," BMC Int Health Hum Rights, vol. 19, no. 1, pp. 18-18, Jun. 2019, doi: 10.1186/s12914-019-0199-1.

[38] K. L. M. Wong, O. J. Brady, O. M. R. Campbell, A. Banke-Thomas, and L. Benova, "Too poor or too far? Partitioning the variability of hospital-based childbirth by poverty and travel time in Kenya, Malawi, Nigeria and Tanzania," International Journal for Equity in Health, vol. 19, no. 1, p. 15, Jan. 2020, doi: 10.1186/s12939-020-1123-y.

[39] S. Saleh et al., "Health seeking for chronic lung disease in central Malawi: Adapting existing models using insights from a qualitative study," PLoS One, vol. 13, no. 12, pp. e0208188-e0208188, Dec. 2018, doi: 10.1371/journal.pone.0208188.

This article is protected by copyright. All rights reserved 
[40] O. Aremu, S. Lawoko, T. Moradi, and K. Dalal, "Socio-economic determinants in selecting childhood diarrhoea treatment options in Sub-Saharan Africa: A multilevel model," Italian journal of pediatrics, vol. 37, p. 13, Mar. 2011, doi: 10.1186/1824-7288-37-13.

[41] A. D. Mebratie, E. Van de Poel, Z. Yilma, D. Abebaw, G. Alemu, and A. S. Bedi, "Healthcare-seeking behaviour in rural Ethiopia: evidence from clinical vignettes," BMJ Open, vol. 4, no. 2, p. e004020, Feb. 2014, doi: 10.1136/bmjopen-2013-004020.

Correspondence: Wingston Ng'ambi, College of Medicine, Lilongwe Campus, P.O. Box 30055, Lilongwe 3, Malawi. Email: wingston.ngambi@gmail.com or wng'ambi@medcol.mw

This article is protected by copyright. All rights reserved 
Table 1: Characteristics of children reporting symptoms and health seeking behaviour of children within the past two weeks in Malawi: 2016

\begin{tabular}{l|l|l|l}
\hline Characteristics & Total $\mathbf{n}(\%)^{\mathrm{a}}$ & $\begin{array}{l}\text { Illness reported in past } \\
\text { two weeks } \mathbf{n}(\%)^{\mathbf{b}}\end{array}$ & $\begin{array}{l}\text { Healthcare sought } \\
\text { for illness reported } \\
\mathbf{n}(\%)^{\mathbf{c}}\end{array}$ \\
\hline Total & $5350(100.0) \quad 1666(31.7)$ & $1008(60.2)$
\end{tabular}

Region

$\begin{array}{llll}\text { North } & 612(11.8) & 185(30.0) & 132(71.7) \\ \text { Central } & 2304(40.5) & 816(38.5) & 467(56.9) \\ \text { Southern } & 2434(47.7) & 665(26.3) & 409(61.2)\end{array}$

Residence

$\begin{array}{llll}\text { Rural } & 4075(82.8) & 1331(33.0) & 768(58.6) \\ \text { Urban } & 1275(17.2) & 335(25.1) & 240(70.7)\end{array}$

Sex

$\begin{array}{llll}\text { Male } & 2564(47.8) & 794(31.0) & 475(60.2) \\ \text { Female } & 2786(52.2) & 872(32.3) & 533(60.3)\end{array}$

Child age group (in years)

$\begin{array}{llll}0-4 & 1792(33.1) & 684(38.0) & 459(66.3) \\ 5-14 & 3558(66.9) & 982(28.5) & 549(56.3)\end{array}$

Wealth status

Low

2242 (44.9) $\quad 778$ (35.1)

425 (54.8)

Middle

$1170(24.1) \quad 349(29.8)$

217 (62.7)

High

$1938(31.0) \quad 539(28.2)$

366 (68.1)

Relationship to household head

Child/niece/nephew

5241 (98.2) $\quad 1649$ (32.0)

997 (60.3)

Brother/sister/cousin

Other relatives

53 (0.9)

6 (14.9)

4 (57.8)

$56(0.9)$

11 (18.1)

7 (56.8)

Age group of carer (in years)

15-34

2464 (44.5) $\quad 811$ (33.4)

509 (61.6)

35-59

2394 (45.7)

698 (30.2)

399 (58.2)

$60+$

492 (9.5)

157 (30.5)

$100(62.8)$

Education level of carer

None

4951 (94.4)

Primary

$194(0.3)$

$1284(32.1)$

$762(59.1)$

This article is protected by copyright. All rights reserved 
${ }^{a}$ Denominator for column of those sick within the past 14 days (b)

${ }^{b}$ Denominator for column of those who sought health care (c) 
Table 2a: Symptoms and their associated health seeking behaviour amongst children in Malawi: 2016

\begin{tabular}{l|l|l}
\hline & & \\
Symptoms (n=1666) & Number of persons for each illness & $\mathbf{n}(\%)$ \\
& & $\begin{array}{l}\text { Number of persons that sought health care for } \\
\text { each illness }\end{array}$ \\
\hline Fever & $\mathbf{n}$ (\%) \\
Respiratory tract & $252(15.1)$ & $569(71.1)$ \\
Headache & $151(9.1)$ & $120(46.6)$ \\
Stomach ache & $128(7.7)$ & $49(32.6)$ \\
Vomiting & $88(5.3)$ & $60(48.7)$ \\
Injury & $79(4.7)$ & $57(60.0)$ \\
Other* & $67(4.0)$ & $34(49.3)$ \\
Skin & $64(3.7)$ & $44(63.1)$ \\
Sore throat & $59(3.5)$ & $47(77.5)$ \\
Eye & $22(1.3)$ & $34(55.4)$ \\
Dental problem & $6(0.4)$ & $14(66.9)$ \\
\hline
\end{tabular}

*Fainting, Pain when Passing Urine, Mental Disorder, Tuberculosis, Unspecified Long-term Illnesses, and Other Illnesses

aDenominator for "Number of children that were taken for health care"

${ }^{b}$ Numerator for children whose carers reported the symptom

This article is protected by copyright. All rights reserved 
Table 2b: Number and percentage of children with chronic conditions in Malawi in 2016

\begin{tabular}{|c|c|c|}
\hline $\begin{array}{l}\text { Chronic condition } \\
(n=1666)\end{array}$ & $\begin{array}{l}\text { Number with } \\
\text { condition }\end{array}$ & $\begin{array}{l}\text { Percentage with } \\
\text { Condition* }\end{array}$ \\
\hline Total & 231 & 13.9 \\
\hline Asthma & 91 & 5.5 \\
\hline Fever & 25 & 1.5 \\
\hline Epilepsy & 24 & 1.4 \\
\hline Stomach Disorder & 17 & 1.0 \\
\hline HIV/AIDS & 11 & 0.7 \\
\hline Mental Illness & 8 & 0.5 \\
\hline TB & 4 & 0.2 \\
\hline Diabetes & 3 & 0.2 \\
\hline Cancer & 3 & 0.2 \\
\hline Pneumonia & 3 & 0.2 \\
\hline Schistosomiasis & 1 & 0.1 \\
\hline Arthritis & 1 & 0.1 \\
\hline
\end{tabular}

*Denominator for each of the chronic conditions is 1666 individuals that reported

$\mathrm{TB}=$ Tuberculosis

HIV/AIDS= Human Immunodeficiency Virus and Acquired Immunodeficiency Syndrome

This article is protected by copyright. All rights reserved 
Table 3: Places where care was sought amongst children with illnesses in Malawi: 2016

\begin{tabular}{|c|c|c|}
\hline Action taken $(n=1666)$ & $\mathbf{n}$ & $\%$ \\
\hline Did not seek health care ${ }^{a}$ & 93 & 5.6 \\
\hline Did nothing, not serious illness & 63 & 3.8 \\
\hline Did nothing, had no money & 30 & 1.8 \\
\hline Sought health care & 1573 & 94.4 \\
\hline (a) Care at health facility ${ }^{b}$ & 1008 & 60.4 \\
\hline Government health facility & 757 & 45.4 \\
\hline CHAM health facility & 51 & 3.1 \\
\hline Private health facility & 146 & 8.8 \\
\hline Village clinic & 28 & 1.7 \\
\hline Local pharmacy* & 26 & 1.6 \\
\hline (b) Care not at health facilities ${ }^{c}$ & 566 & 34.0 \\
\hline Used medicine had in stock & 105 & 6.3 \\
\hline Personally, known remedies & 19 & 1.1 \\
\hline Grocery & 408 & 24.5 \\
\hline Traditional healer & 8 & 0.5 \\
\hline Faith healer & 13 & 0.8 \\
\hline Other & 13 & 0.8 \\
\hline
\end{tabular}

CHAM=Christian Health Association of Malawi

${ }^{b}$ These constitute healthcare seeking behaviour (HSB)

a,cThese do not constitute healthcare seeking behaviour (HSB)

*Pharmacists provide some level of health care advice so we considered this as heath care seeking behaviour. Using drug at home or buying from a grocery store does not involve receiving any health care advice.

This article is protected by copyright. All rights reserved 
Table 4: Factors associated with health seeking behaviour amongst children in Malawi for whom at least one symptom was reported: 2016

\begin{tabular}{|c|c|c|c|c|}
\hline \multirow{2}{*}{ Characteristics $(n=1666)$} & \multicolumn{2}{|l|}{ Crude } & \multicolumn{2}{|l|}{ Adjusted } \\
\hline & OR (95\%Cl) & P-value* & OR $(95 \% \mathrm{Cl})$ & P-value* \\
\hline \multicolumn{5}{|l|}{ Region } \\
\hline North & 1.00 & & 1.00 & \\
\hline Central & $0.48(0.29-0.80)$ & 0.01 & $0.42(0.24-0.72)$ & 0.00 \\
\hline Southern & $0.63(0.38-1.07)$ & 0.09 & $0.55(0.32-0.96)$ & 0.04 \\
\hline \multicolumn{5}{|l|}{ Residence } \\
\hline Rural & 1.00 & & 1.00 & \\
\hline Urban & $2.20(1.52-3.17)$ & 0.08 & $1.75(1.12-2.72)$ & 0.014 \\
\hline \multicolumn{5}{|l|}{ Sex } \\
\hline Male & 1.00 & & 1.00 & \\
\hline Female & $1.08(0.84-1.39)$ & 0.54 & $1.13(0.86-1.47)$ & 0.38 \\
\hline \multicolumn{5}{|c|}{ Age group of carer (in years) } \\
\hline $15-34$ & 1.00 & & & \\
\hline $35-59$ & $0.76(0.56-1.03)$ & 0.08 & & \\
\hline $60+$ & $1.07(0.63-1.81)$ & 0.81 & & \\
\hline \multicolumn{5}{|l|}{ Child age group (in years) } \\
\hline $0-4$ & 1.00 & & 1.00 & \\
\hline $5-14$ & $0.51(0.39-0.67)$ & $<0.001$ & $0.50(0.37-0.67)$ & $<0.001$ \\
\hline \multicolumn{5}{|c|}{ Education level of household head } \\
\hline None & 1.00 & & & \\
\hline Primary & $1.61(0.69-3.74)$ & 0.27 & & \\
\hline
\end{tabular}

This article is protected by copyright. All rights reserved 
Secondary

Tertiary

Wealth status

Low

Middle

High

Relationship to household head

Child/niece/nephew

Brother/sister/cousin

Other relatives

Presence vs. absence of illness

Fever

Vomiting

Stomachache

Sore throat

Respiratory infections

Headache

Skin diseases

Dental problem

Injury

Eye problem

Other symptoms**

Had chronic conditions $\Sigma$
$2.25(0.93-5.47)$

$2.17(0.29-15.99)$

1.00

$1.53(1.06-2.22)$

$2.16(1.55-3.02)$

1.00

1.04 (0.09-11.44)

$0.78(0.16-3.78)$

3.47 (2.60-4.64)

$1.27(0.72-2.23)$

$0.48(0.30-0.76)$

$0.88(0.44-1.77)$

$0.46(0.32-0.66)$

$0.20(0.13-0.33)$

2.33 (1.13-4.78)

$0.33(0.04-2.86)$

0.37 (0.20-0.67)

$1.16(0.38-3.53)$

$1.36(0.70-2.64)$
0.07

0.45

$\begin{array}{lll} & 1.00 & \\ 0.024 & 1.64(1.10-2.43) & 0.01 \\ <0.001 & 1.86(1.25-2.78) & 0.02\end{array}$

0.97

0.76

$\begin{array}{lll}<0.001 & 3.52(1.95-6.37) & <0.001 \\ 0.40 & 1.64(0.76-3.54) & 0.20 \\ 0.002 & 0.82(0.43-1.58) & 0.56 \\ 0.72 & 1.36(0.58-3.19) & 0.49 \\ <0.001 & 0.66(0.36-1.21) & 0.18 \\ <0.001 & 0.47(0.24-0.92) & 0.03 \\ 0.02 & 3.45(1.37-8.72) & 0.01 \\ 0.32 & 0.49(0.05-4.74) & 0.53 \\ 0.31 & 0.67(0.30-1.48) & 0.32 \\ 0.80 & 1.55(0.45-5.39) & 0.49 \\ 0.37 & 1.73(0.75-4.06) & 0.20\end{array}$

This article is protected by copyright. All rights reserved 
*P-values from multi-level logistic regression

**Fainting, Pain when Passing Urine, Mental Disorder, Tuberculosis, Unspecified Long-term IIInesses, and Other IIInesses

¿Fever, tuberculosis, HIV/AIDS, diabetes, asthma, schistosomiasis, arthritis, epilepsy, stomach disorder, cancer, pneumonia and mental illness

This article is protected by copyright. All rights reserved 